\title{
Neonatal screening for congenital hypothyroidism in an Italian Centre: a 5-years real-life retrospective study
}

\author{
Maria Cristina Maggio ${ }^{1 *}$ (D), Saveria Sabrina Ragusa', Tommaso Silvano Aronica², Orazia Maria Granata²,
} Eleonora Gucciardino ${ }^{2}$ and Giovanni Corsello ${ }^{1}$

\begin{abstract}
Introduction: Congenital hypothyroidism is an endocrine disease with a significant incidence in the general population (1:2000-1:3000 newborns in Italy) and a different geographical distribution, partially explained by endemic iodine deficiency, genetic traits and autoimmune thyroid diseases.
\end{abstract}

Objectives: Aims of this study are: to evaluate the incidence of positive neonatal blood spot screening for $\mathrm{CH}$ in western Sicily, identified by the screening centre of the Children Hospital "G. Di Cristina", ARNAS, Palermo; to evaluate the impact of a lower TSH cutoff in the neonatal blood spot screening for $\mathrm{CH}$.

Materials and methods: The TSH threshold of the neonatal screening was established as $\geq 6 \mathrm{mU} / \mathrm{L}$ of whole blood. We analysed the screening centre data in the period January 2013-April 2018, for a total number of 85.373 babies (45.7\% males; $54.3 \%$ females).

Results: 4.082 Babies (4.8\%) required a second screening. Among these, $372(0.44 \%)$ were out of range. The diagnosis of congenital hypothyroidism (CH) was confirmed in 182 babies (0.21\%). 77/372 newborns (20.7\%) with confirmed high TSH levels showed whole blood TSH levels $\geq 6-<7 \mathrm{mU} / \mathrm{L}$.

In synthesis, $48.9 \%$ of the out of range re-testing had a confirmed diagnosis of $\mathrm{CH}$.

Conclusion: The reduction of TSH cutoff to $6 \mathrm{mU} / \mathrm{L}$ allowed to identify 77/372 neonates (20.7\%) with confirmed out of range TSH, otherwise not recruited by the previously employed TSH cutoff.

Keywords: Congenital hypothyroidism, Neonatal screening, Twins, TSH, lodine deficiency

\section{Introduction}

Congenital hypothyroidism $(\mathrm{CH})$ occurs in approximately 1:2000-1:3000 neonates in Italy, with possible geographical differences, attributable to the genetic background, to a different incidence of autoimmune thyroiditis between young adult women and to the presence

\footnotetext{
* Correspondence: mariacristina.maggio@unipa.it

'Department of Health Promotion Sciences, Maternal and Infantile Care, Internal Medicine and Medical Specialities PROMISE, "G. D'Alessandro", University of Palermo, Via del Vespro 133, 90127 Palermo, Italy

Full list of author information is available at the end of the article
}

of endemic zones in the region characterized by iodine deficiency.

$\mathrm{CH}$ may be permanent or transient: this condition needs a well-defined follow up, concorded with the family. An appropriate follow up allows to decide to try discontinuing l-thyroxine treatment, especially in children with mild increase of TSH levels in neonatal age, in preterm infants, in sons of mothers with autoimmune thyroiditis.

Children with $\mathrm{CH}$ will develop severe intellectual disability, showing an intelligence quotient lower than 70 . However, more than $95 \%$ of neonates with $\mathrm{CH}$ have few,

(C) The Author(s). 2021 Open Access This article is licensed under a Creative Commons Attribution 4.0 International License, which permits use, sharing, adaptation, distribution and reproduction in any medium or format, as long as you give appropriate credit to the original author(s) and the source, provide a link to the Creative Commons licence, and indicate if changes were made. The images or other third party material in this article are included in the article's Creative Commons licence, unless indicated otherwise in a credit line to the material. If material is not included in the article's Creative Commons licence and your intended use is not permitted by statutory regulation or exceeds the permitted use, you will need to obtain permission directly from the copyright holder. To view a copy of this licence, visit http://creativecommons.org/licenses/by/4.0/ The Creative Commons Public Domain Dedication waiver (http://creativecommons.org/publicdomain/zero/1.0/) applies to the data made available in this article, unless otherwise stated in a credit line to the data. 
if any, clinical manifestations of hypothyroidism. For this reason, neonatal screening allows the precocious diagnosis of $\mathrm{CH}$ and supports timely the l-thyroxine replacement therapy preventing or mitigating this intellectual disability [1].

The prognosis of infants identified by screening and who started the treatment early is excellent, with IQ similar to controls. A lower neurocognitive outcome may occur in those infants who started l-thyroxine later (> 30 days of age), or with lower l-thyroxine doses than currently recommended, and in those infants with more severe $\mathrm{CH}$.

Lowering the TSH cutoff was the most important factor contributing to increasing the number of diagnoses of $\mathrm{CH}$ in Italy. Irreversible effects of $\mathrm{CH}$ on central nervous system development can be reversible in case of a treatment without delay; hence, a neonatal mass screening program provides the best instrument for early diagnosis and treatment [1].

Neonatal screening should detect all forms of primary $\mathrm{CH}$ : mild, moderate, and severe. However, those patients with severe $\mathrm{CH}$ in whom morbidity is high need a prompt diagnosis permitted only by neonatal screening. The most sensitive test for the identification of primary $\mathrm{CH}$ is the determination of TSH blood levels. The best "window" for testing is between 48 and $72 \mathrm{~h}$ of age. Blood is spotted onto blood collection paper, dried and eluted into a buffer for TSH analysis. This method identifies primary $\mathrm{CH}$ more successfully than primary $\mathrm{T} 4$ screening.

The goal of an efficient neonatal blood spot screening program is to perform an early diagnosis and treatment in children with $\mathrm{CH}$ : this strategy successfully prevents delayed growth and neurological deficiency [1-3].

Aims of this study are to assess:

- the prevalence of $\mathrm{CH}$ in western Sicily, evaluated by the single screening centre of the Children Hospital "G. Di Cristina", ARNAS, Palermo, Italy;

- the impact of a lower cutoff for TSH in the identification of neonates with $\mathrm{CH}$ and the estimation of potential missing diagnosis with a higher cutoff $[4,5]$.

\section{Materials and methods}

All infants with screening blood spot TSH (capillary whole blood) $\geq 6 \mathrm{mU} / \mathrm{L}$ underwent confirmatory diagnostic testing.

We performed a retrospective analysis of neonatal screening data, diagnosis and treatment procedures performed for $\mathrm{CH}$ and collected in one of the two Sicily's screening centers from January 2013 to April 2018. All the neonates who showed the first screening out of range, were retested. In consideration of TSH values and the age of the patient, the retesting was performed at the same time of the TSH, fT3, fT4, anti-thyroglobulin antibodies, anti-thyroid peroxidase antibodies serum dosage. When the diagnosis of $\mathrm{CH}$ was confirmed, the patients underwent thyroid scan and/or thyroid scan and scintigraphy.

The neonates with a confirmed diagnosis of $\mathrm{CH}$ started treatment with L-thyroxine when the diagnosis was confirmed and are still followed in our paediatric endocrinology unit.

We considered the possible TSH cutoff and compared the number of $\mathrm{CH}$ diagnosis if the cutoff was considered as $\geq 6-<7 \mathrm{mU} / \mathrm{L} ; \geq 7-<10 \mathrm{mU} / \mathrm{L} ; \geq 10 \mathrm{mU} / \mathrm{L}$ and compared the number and the percentage of neonates resulted positive to the screening every year. We considered with the three possible cutoffs the number of confirmed permanent or transient $\mathrm{CH}$ who started treatment, as well.

\section{Results}

A total number of 85.373 babies $(45.7 \%$ males; $54.3 \%$ females) were screened. $11.3 \%$ were preterm neonates. $12.2 \%$ were sons of immigrant mothers, highlighting the high incidence of multiethnicity of the population. 3\% had malformations in association with $\mathrm{CH} .4 .082$ neonates $(4.8 \%)$ were recalled for a second screening, in consideration of out of range or uncertain results (borderline values, comorbidities, preterm birth, etc). Among these, $372(0.44 \%)$ were out of range. The diagnosis of congenital hypothyroidism $(\mathrm{CH})$ was confirmed in 182 babies $(0.21 \%)$. In synthesis, $48.9 \%$ of the out of range re-testing had a confirmed diagnosis of $\mathrm{CH}$.

The confirmed diagnosis of $\mathrm{CH}$ in the period of the study was catalogued considering the birth year, as shown in Table 1.

The incidence of agenesis varied from a peak of $16 \%$ in 2014 to a nadir of $0 \%$ thyroid aplasia in 2017-2018 (see Table 2). However, the numbers of thyroid agenesis are too low to settle any conclusion.

The $6 \%$ of patients with a confirmed diagnosis of $\mathrm{CH}$ were preterm neonates: among those, gestational age ranged between 26 and 34 weeks and birth weight ranged between 800 and $1500 \mathrm{~g} ; 4.9 \%$ were twins [6] with a concordance of the diagnosis of $\mathrm{CH}$ of $44.4 \%$. Furthermore, anamnestic records revealed that $38.2 \%$ were born by a caesarean delivery. $12 \%$ had the mother with an autoimmune thyroid disease; $29 \%$ had one or more first and/or second-degree relatives affected by thyroid dysfunction.

Twins with a diagnosis of $\mathrm{CH}$, followed in our centre, are all still treated with L-thyroxine.

In $3.8 \%$ of all the patients with confirmed hypothyroidism, other congenital anomalies were documented, mainly cardiac malformations. Three childrens 
Table 1 Cases of $\mathrm{CH}$ in the different years, according to TSH value

\begin{tabular}{lllllll}
\hline Year & $\begin{array}{l}\text { Screening } \\
\text { number }\end{array}$ & $\begin{array}{l}\text { Second screening/screening } \\
\text { number }\end{array}$ & $\begin{array}{l}\text { Increased TSH/second } \\
\text { screening }\end{array}$ & $\begin{array}{l}\text { TSH } \geq 6-<7 \\
\mathbf{m U / L} \\
\text { /increased } \\
\text { TSH }\end{array}$ & $\begin{array}{l}\text { TSH } \geq 7-<10 \\
\text { mU/L } \\
\text { /increased TSH }\end{array}$ & $\begin{array}{l}\text { TSH } \geq 10 \\
\text { mU/L } \\
\text { /increased } \\
\text { TSH }\end{array}$ \\
\hline 2013 & 17.472 & $941(5.4 \%)$ & $50(5.3 \%)$ & $7(14 \%)$ & $17(34 \%)$ & $26(52 \%)$ \\
2014 & 16.020 & $680(4.2 \%)$ & $40(5.8 \%)$ & $3(7.5 \%)$ & $13(32.5 \%)$ & $24(60 \%)$ \\
2015 & 15.502 & $627(4 \%)$ & $62(48.8 \%)$ & $10(16.1 \%)$ & $20(32.2 \%)$ & $32(51.6 \%)$ \\
2016 & 15.670 & $659(4.2 \%)$ & $80(12.1 \%)$ & $19(23.7 \%)$ & $26(32.5 \%)$ & $35(43.7 \%)$ \\
2017 & 15.037 & $838(5.6 \%)$ & $98(11.6 \%)$ & $28(28.5 \%)$ & $40(40.8 \%)$ & $30(30.6 \%)$ \\
2018 (Jan- & 5.672 & $337(5.9 \%)$ & $42(12.5 \%)$ & $10(23.8 \%)$ & $17(40.4 \%)$ & $15(35.7 \%)$ \\
Apr) & & & & & & \\
\hline
\end{tabular}

showed cardiac defects, 2 patients showed genitourinary system malformations, 1 patient was born with esophageal atresia. Nevertheless, these patients had no documented genetic or chromosomal syndromes.

In order to evaluate the influence of the TSH value cutoff at the screening, we split the sample according to TSH spot levels per volume of whole blood, as performed in neonatal screening $(\geq 6-<7 \mathrm{mU} / \mathrm{L} ; \geq 7-<10$ $\mathrm{mU} / \mathrm{L} ; \geq 10 \mathrm{mU} / \mathrm{L})$. In the 3 groups we evaluated the total number of babies with confirmed $\mathrm{CH}$, transient or permanent (Table 1).

The diagnosis of thyroid in situ, aplastic thyroid or hypoplastic thyroid varied in the different years, however with a significant prevalence of thyroid in situ (Table 2).

Serum TSH levels per serum equivalent volume were the highest in neonates with thyroid agenesis; further, in the group of patients with thyroid hypoplasia, TSH serum levels were higher than in neonates with thyroid in situ (Table 3).

The neonates with a confirmed diagnosis of $\mathrm{CH}$ started treatment with L-thyroxine before the 14th day of life $(45.3 \%)$, before the 21 st day of life $(41.2 \%)$, after the 21 st day of life $(13.5 \%)$ when the diagnosis was confirmed later (preterm infants, late increase of TSH, etc), and are still followed in our paediatric endocrinology unit. At the date, $73.9 \%$ are still in treatment with Lthyroxine.

170/182 among the patients who started L-thyroxine are still followed in our operative unit. The mean TSH value, 14 days after L-thyroxine treatment was started, was $3.38 \mu \mathrm{U} / \mathrm{ml}$ (range: $0.02-14.03$ ), with the prompt and progressive normalization of endocrine profile.

$11 \%$ of the neonates who started treatment with $\mathrm{L}$ thyroxine had the mother with an autoimmune thyroid disease; otherwise, the $30 \%$ had one or more between the first and/or the second-degree relatives affected by thyroid dysfunction.

The reduction of TSH cutoff to $6 \mathrm{mU} / \mathrm{L}$ allowed to identify $77 / 372$ neonates (20.7\%) with confirmed out of range TSH. These patients would have been missed at the screening if the cutoff had been higher.

Some patients were found out, even if they showed a TSH level lower than $6 \mathrm{mU} / \mathrm{L}$ at the first screening (Table 3), because their screening was performed again some days later and the serum TSH levels were detected. These patients were: neonates who underwent a too early discharge from the hospital; preterm or neonates at risk to develop hypothyroidism for autoimmune thyroiditis of the mother; twins with pathological neonatal screening or a confirmed diagnosis of $\mathrm{CH}$.

\section{Discussion}

Considering the high rate of $\mathrm{CH}$ in our population of western Sicily, we stratified the sample analysed according to TSH levels relieved at the screening. We confirmed that a significant number of babies could not be detected by the screening if a cutoff $>7 \mathrm{mU} / \mathrm{L}$ is chosen. In fact, $20.7 \%$ of the patients, otherwise confirmed as $\mathrm{CH}$, showed TSH blood spot levels $\geq 6-<7 \mathrm{mU} / \mathrm{L}$.

Recall rates in different centres for $\mathrm{CH}$ neonatal screening range from 0.01 to $13.3 \%$; the difference is

Table 2 Different distribution per year of agenesis, hypoplasia or thyroid in situ in patients with confirmed diagnosis of $\mathrm{CH}$

\begin{tabular}{llllll}
\hline Year & Confirmed diagnosis of CH/high TSH at the second screening & agenesis & hypoplasia & Ectopic gland & Thyroid in situ \\
\hline 2013 & $32(64 \%)$ & $3(9.4 \%)$ & $7(21.87 \%)$ & $1(3.1 \%)$ & $21(65.6 \%)$ \\
2014 & $25(62.5 \%)$ & $4(16 \%)$ & $9(36 \%)$ & 0 & $12(48 \%)$ \\
2015 & $37(59.6 \%)$ & $2(5.4 \%)$ & $8(21.6 \%)$ & 0 & $27(72.9 \%)$ \\
2016 & $42(52.5 \%)$ & $2(4.8 \%)$ & $3(7.1 \%)$ & $1(2.4 \%)$ & $36(85.7 \%)$ \\
2017 & $32(32.6 \%)$ & 0 & $5(15.6 \%)$ & $1(3.1 \%)$ & $26(81.2 \%)$ \\
$2018(J a n-A p r)$ & $14(33.3 \%)$ & 0 & $2(14.3 \%)$ & $1(7.1 \%)$ & $11(78.5 \%)$ \\
\hline
\end{tabular}


Table 3 Bloodspot and serum TSH levels in correlation with thyroid morphology

\begin{tabular}{llll}
\hline & $\begin{array}{l}\text { Thyroid agenesis (Median: } \\
\text { range) }\end{array}$ & $\begin{array}{l}\text { Thyroid hypoplasia (Median: } \\
\text { range) }\end{array}$ & $\begin{array}{l}\text { Thyroid in situ (Median: } \\
\text { range) }\end{array}$ \\
\hline $\begin{array}{l}\text { Bloodspot TSH levels }(\mathrm{mU} / \mathrm{L}) \text { (first screening) } \\
\text { Bloodspot TSH levels }(\mathrm{mU} / \mathrm{L}) \text { (second }\end{array}$ & $134: 6.2-319$ & $16.8: 4.2-266.7$ & $9.4: 0.85-225$ \\
$\begin{array}{l}\text { screening) } \\
\text { Serum TSH levels }(\mu \mathrm{l} / \mathrm{m} / \mathrm{ml})\end{array}$ & $354: 9.3-462$ & $17.9: 9.3-231$ & $14.5: 21.39-241$ \\
\hline
\end{tabular}

linked to various screening methods as screening protocols (use of TSH and T4 or TSH alone), different laboratory techniques and kits, site of sample collection, and different cutoffs. Iodine status is a relevant factor: the control of iodine deficiency, and the use of iodine free antiseptic during delivery are contributing factors for the raise of TSH levels. Recall rate is higher in counties with a higher $\mathrm{CH}$ incidence [7] and both are documented in our population.

Iodine deficiency is the most important cause of $\mathrm{CH}$ worldwide. Iodine is essential for thyroid hormone synthesis and is present in air, soil and water.

The high incidence of positive anamnestic records confirming thyroid disease in the mother and/or in firstand/or second-degree relatives, supports the hypothesis that the high incidence of $\mathrm{CH}$ in Sicily could be linked to geographical and/or endemic conditions, genetic background or lack of iodine supplementation in rural or urban areas where iodine deficiency is still endemic, because of the low iodine concentrations in water and other iodine sources. In fact, western Sicily has several small towns historically built on hills or mountains, with iodine deficiency. The Iodine supplementation campaign was well done in the past decades, however residents reduced adherence in the last years [8]. Furthermore, consanguineous unions are more frequent in small towns, especially in rural zones. In this contest, inherited diseases transmission is higher, as $\mathrm{CH}$ secondary to enzymatic defects or receptor mutations. Moreover, autoimmune thyroiditis shows a higher incidence in some areas of western Sicily, increasing the risk of transient or permanent $\mathrm{CH}$.

\section{Conclusions}

Transient hypothyroidism may occur frequently, however infants should be treated with L-thyroxine for the first 3 years of life, considering the risk of growth delay and mental retardation, considering abating the danger for neonatal central nervous system by stabilizing thyroid function. A new evaluation after the age of 3 years is required in these patients, after a withdrawal of the replacement therapy with $\mathrm{L}$ thyroxine, to confirm the persistence of $\mathrm{CH}$.

The goal of initial therapy in $\mathrm{CH}$ is to minimize neonatal central nervous system exposure to hypothyroidism by normalizing thyroid function, as soon as possible.
Lowering TSH cutoff to $6 \mathrm{mU} / \mathrm{L}$ allowed recognising $20.7 \%$ of neonates with confirmed high TSH levels, otherwise not recruited by the previously employed TSH cutoff.

With this cutoff, we detected additional cases of permanent $\mathrm{CH}$, a number of which showed defects of thyroid embryogenesis and severe hypothyroidism at the confirmation of the diagnosis by serum levels of fT4, fT3 and TSH and by ultrasound and/or scintigraphy.

However, the age of 3 years was not reached by all the children at the time of the collection of the study data. Considering this, by 3-year follow-up, we have not yet the data to differentiate the number of children with confirmed permanent $\mathrm{CH}$, or the number of children who tried to stop l-thyroxine and the number of children who did not further require L-thyroxine.

Further studies have to confirm the real prevalence of transient hypothyroidism in children positive to the neonatal screening, confirmed by serum levels of TSH, fT4 and fT3 in western Sicily, and the possible prevention strategies necessary to reduce these numbers and ameliorate the follow-up and the clinical outcome of these children.

It is suitable to implement valid interventions to reduce $\mathrm{CH}$, controlling iodine deficiency and employing iodinefree antiseptic solutions during delivery. Furthermore, preterm and/or low birth weight neonates, twins, sons of mothers with autoimmune thyroiditis or diabetes, can show a late increase of TSH levels: in these patients neonatal screening must be repeated at 14 days from birth [9, 10]. Above all, the incidence of $\mathrm{CH}$ is higher in multiple deliveries compared with single deliveries and twins frequently show concordance in developing hypothyroidism, when one twin is affected [6]. In these cases, follow-up is needed and must be considered a second thyroid screening and/or serum TSH and fT4 detection at 14 days from birth to avoid delay in the diagnosis. The misdiagnosis potential risk must be clearly explained to the parents and the paediatric endocrinologist must be sure that blood controls are well done also to initially euthyroid twins.

The goal of a $\mathrm{CH}$ screening program is to provide the optimal quality of life and the best neurocognitive development for babies with mild as well as with severe $\mathrm{CH}$ [2]. The authors hallmark the require of establishing the optimal TSH cutoff in the screening program in various settings, and of achieving screening benefits considering the geographical area peculiarities. 


\section{Abbreviation}

$\mathrm{CH}$ : Congenital hypothyroidism

\section{Acknowledgements}

The authors would like to acknowledge the participants of the study and their parents/legal guardians for their collaboration.

\section{Authors' contributions}

Conceptualization: SSR and MMC; Methodology: MMC and SSR; Data Collection: OMG, TSA and EG; Data Analysis: MMC, GC and SSR; Data interpretation: MMC and SSR; Writing - Original Draft Preparation: MMC; Writing - Editing: MMC and GC; Writing - Review: GC and MMC. All authors read and approved the final manuscript.

\section{Funding}

The authors declare that they have not received funding.

\section{Availability of data and materials}

The datasets used and/or analysed during the current study are available from the corresponding author on reasonable request.

\section{Declarations}

\section{Ethics approval and consent to participate}

Not applicable for this study; the typology of the study does not require the local ethics committee approval.

\section{Consent for publication}

Not applicable.

\section{Competing interests}

The authors declare that they have no competing interests.

\section{Author details}

'Department of Health Promotion Sciences, Maternal and Infantile Care, Internal Medicine and Medical Specialities PROMISE, "G. D'Alessandro", University of Palermo, Via del Vespro 133, 90127 Palermo, Italy. ${ }^{2}$ U.O.S. Screening Neonatale e Metabolico Allargato of the Children Hospital "G. Di Cristina", ARNAS, Palermo, Italy.

Received: 14 May 2020 Accepted: 21 April 2021

Published online: 05 May 2021

\section{References}

1. Léger J, Olivieri A, Donaldson M, Torresani T, Krude H, van Vliet G, et al. ESPE-PES-SLEP-JSPE-APEG-APPES-ISPAE; Congenital Hypothyroidism Consensus Conference Group. European Society for Paediatric Endocrinology consensus guidelines on screening, diagnosis, and management of congenital hypothyroidism. J Clin Endocrinol Metab. 2014 Feb;99(2):363-84. https://doi.org/10.1210/jc.2013-1891.

2. Grosse SD, Van Vliet G. Prevention of intellectual disability through screening for congenital hypothyroidism: how much and at what level? Arch Dis Child. 2011;96(4):374-9. https://doi.org/10.1136/adc.2010.190280.

3. Gruters A, Jenner A, Krude H. Long-term consequences of congenital hypothyroidism in the era of screening programmes. Best Pract Res Clin Endocrinol Metab. 2002;16(2):369-82. https://doi.org/10.1053/beem.2002.0202.

4. Olivieri A, Corbetta C, Weber G, Vigone MC, Fazzini C, Medda E, et al. Congenital hypothyroidism due to defects of thyroid development and mild increase of TSH at screening: data from the Italian National Registry of infants with congenital hypothyroidism. J Clin Endocrinol Metab. 2013;98(4): 1403-8. https://doi.org/10.1210/jc.2012-3273.

5. Knowles RL, Oerton J, Cheetham T, Butler G, Cavanagh C, Tetlow L, et al. Newborn screening for primary congenital hypothyroidism: estimating test performance at different TSH thresholds. J Clin Endocrinol Metab. 2018; 103(10):3720-8. https://doi.org/10.1210/jc.2018-00658.

6. Medda E, Vigone MC, Cassio A, Calaciura F, Costa P, Weber G, et al. Neonatal screening for congenital hypothyroidism: what can we learn from discordant twins? J Clin Endocrinol Metab. 2019;104(12):5765-79. https://doi. org/10.1210/jc.2019-00900.

7. Mehran L, Khalili D, Yarahmadi S, Amouzegar A, Mojarrad M, Ajang N, et al, Worldwide Recall Rate in Newborn Screening Programs for Congenital
Hypothyroidism. Int J Endocrinol Metab. 2017;15(3):e55451. https://doi.org/1 0.5812/ijem.55451.

8. Regalbuto C, Salamone S, La Rosa GL, Calaciura F, Buscema M, Vigneri R. Iodine deficiency and iodine prophylaxis experience in Sicily. Ann Ist Super Sanita. 1998;34(3):429-36.

9. Bijarnia S, Wikcken B, Wiley V. Newborn screening for congenital hypothyroidism in very-low-birth-weight babies: the need for a second test. J Inherit Metab Dis. 2011;34(3):827-33. https://doi.org/10.1007/s10545-0119286-8.

10. Fisher DA. Thyroid function and dysfunction in premature infants. Pediatr Endocrinol Rev. 2007;4(4):317-28.

\section{Publisher's Note}

Springer Nature remains neutral with regard to jurisdictional claims in published maps and institutional affiliations.

\section{Ready to submit your research? Choose BMC and benefit from:}

- fast, convenient online submission

- thorough peer review by experienced researchers in your field

- rapid publication on acceptance

- support for research data, including large and complex data types

- gold Open Access which fosters wider collaboration and increased citations

- maximum visibility for your research: over $100 \mathrm{M}$ website views per year

At BMC, research is always in progress.

Learn more biomedcentral.com/submissions 